\title{
Differential proteomic analysis to identify proteins associated with Tenderness of Yak meat from different parts based on TMT Proteomic
}

\author{
Zhongxin YAN ${ }^{1,2,3}$ (D), Zhoumin $\mathrm{LU}^{1 *}$ (D), Wei $\mathrm{LI}^{2}$, Rong $\mathrm{HU}^{2}$, Qingmei MA ${ }^{4}$
}

\begin{abstract}
In order to study the tenderness mechanism of difference in different parts of Yak meat, the differentially expressed proteins (DEPs) and its correlation with quality of Yak meat were studied by TMT (Tandem Mass Tags, TMT) quantitative proteomic method. The results showed that 25, 40 and 34 DEPs were identified in JR/HGT, WJR/HGT and WJR/JR groups, respectively. Correlation analysis between DEPs and quality traits of yak meat showed that there were 12 DEPs with significant correlation were correlated closely with quality traits. The relative contents of the 11 DEPs were significantly different in different parts $(\mathrm{p}<0.05)$.There are 8, 9 and 6 key DEPs in JR/HGT, WJR/HGT and WJR/JR groups, respectively.The expression of these DEPs were down-regulated and up-regulated in different parts, and was closely related to the cell growth and death, carbohydrate metabolism, amino acid metabolism, protein binding, motility activity and unfolded protein binding. The significant difference of the expression of these key proteins in different parts is the internal reason of the difference of quality traits among WJR, JR and HGT.This provide a reference for the study on the mechanism of difference in Yak meat.
\end{abstract}

Keywords: yak meat; different parts; TMT proteomic; tenderness; correlation analysis.

Practical Application: The analysis provide a reference for the study on the mechanism of difference in Yak meat.

\section{Introduction}

The yak (Bos grunniens) are mainly distributed in the QinghaiTibet Plateau and adjacent areas of China, with a population of more than 14 million, accounting for more than $90 \%$ of the world's total yak population (Zhang et al., 2015). Yak can adapt to the harsh environment of low temperature, hypoxia and high solar radiation on the Qinghai-Tibet Plateau, and yak breeding is an important economic source for herdsmen in pastoral areas on the Qinghai-Tibet Plateau (Hardie et al., 2012). In recent years, people consume more and more beef, and pay more attention to the quality of beef and beef products (McCarthy et al., 2017). Yak meat is a kind of meat with high protein, low fat and rich in various fatty acids and amino acids (Guo et al., 2021), which is more and more favored by consumers. Tenderness is an important index to measure meat quality, and the factors that affect meat tenderness include variety, age, muscle position, feeding and post-slaughter maturation process (Park et al., 2010; Taye et al., 2018). Different protein composition and structural traits directly affect the physicochemical properties and tenderness quality of muscle (Park et al. 2010; Almeida et al., 2015). Due to the coarse muscle fiber, the tenderness quality of yak meat is poor. For improving the quality of yak meat tenderness, scholars have done a lot of research on effect of endogenous protease (Li et al. 2020; Tian et al., 2013), myofibril protein (Yang et al., 2019), reactive oxygen species (Wang et al., 2018a), processing and mature manner (Gao et al., 2020; Chen et al., 2020) and the intracellular environment (Wang et al., 2017) on the quality of tenderness after the slaughter. However, there are few reports on the mechanism of the difference of tenderness quality traits in different parts of yak meat by proteomics.

Proteomics are a tool for understanding the biological information of muscle quality and helps to clarify the mechanism of differences in meat quality traits (Wang et al., 2016). TMT technique is a relative and absolute quantitative technique for the same isotope labeling in vitro. At present, proteomics methods have been applied to the study of biological information and marker proteins such as muscle tenderness (Beldarrain et al., 2018; Gagaoua et al., 2018), color (Yu et al., 2018) and Water holding capacity (Zhang et al., 2019a; Zuo et al., 2016). The correlation between characteristic differential proteins and muscle quality traits has been further analyzed (Shi et al., 2018; Cao et al., 2019). In order to understand the correlation between differential protein of different parts of yak meat and quality traits, and clarify the heterogeneity mechanism of different parts of yak meat, we selected the three different parts of the yak meat in this study, differential proteins were analyzed by TMT proteomic, and the shear force, cooking loss rate and the quality and structure properties indexes were determined, Correlation analysis and expression level analysis were used to explore the mechanism of quality difference between different parts of yak meat, in 
order to provide theoretical reference for further study on the heterogeneity and quality control of different parts of yak meat.

\section{Materials and methods}

\subsection{Sample}

The author has collected 9 killed bulls-at average live body weights of $248.6 \pm 16.7 \mathrm{~kg}$ and at the age of $36 \pm 2$ months-as samples (WJR, HFT and JR), from a commercial slaughterhouse - Xiahua Hala Food Co., Ltd. in Haiyan City, Qinghai Province, China. It took 60 minutes to gather meat samples after the post-mortem. Every group includes three biological replicates. The researcher has cut about $5 \mathrm{~g}$ of the sample into slight pieces and frozen them with liquid nitrogen ahead of analyzing proteomics. About $200 \mathrm{~g}$ were captured in the yak meat, mixed with ice and transported to the laboratory immediately.

\subsection{Quality traits determination}

About $100 \mathrm{~g}$ yak muscle was cooked in the cooking bag at $80{ }^{\circ} \mathrm{C}$ until the core temperature reached $75^{\circ} \mathrm{C}$ (Zhang et al., 2019b). TPA (The texture profile analysis) was performed by using a CT3 texture analyzer (Brookfield Engineering Laboratories, Inc., USA). A square probe (TA3/100) was pressed against the second segment of yak muscle at a constant speed of $1.5 \mathrm{~mm} / \mathrm{s}$ for two consecutive cycles, using $50 \%$ compression for each sample. The textural traits were expressed as hardness,elasticity and chewiness (Hou et al., 2014). Warner-Bratzler shear force (WBSF) was performed by using a CT3 texture analyzer (Brookfield Engineering Laboratories, Inc., USA) and tested by using a Warner-Bratzler V-shaped shearing device with a cross head speed of $1.0 \mathrm{~mm} / \mathrm{s}$ (Zhang et al., 2019b; Hou et al., 2014). The shear force recorded in kilogram $(\mathrm{kg})$. All determinations were performed in triplicate.

\subsection{Proteomic analysis}

Total Protein Extraction,Peptide Preparation,TMT Labeling of Peptides,HPLC Fractionation and LC-MS/MS Analysis. The identification and quantization of protein were performed by following the method of Yan et al. (2021).

\subsection{Bioinformatics and statistical analysis}

The investigation of GO (Gene Ontology) was carried out by employing interproscan- 5 program against non-redundant protein database, which contains ProDom, Pfam, ProSiteProfiles, SMART, PANTHER, PRINTS (Jones et al., 2014) and Kyoto
Encyclopedia of Genes and Genomes (KEGG), to examine pathways and protein families.For quality parameters among different groups (JR, HGT and WJR), means were compared with ANOVA using SPSS 22.0 system and differences were considered significant at $\mathrm{P}<0.05$. The results were expressed as means \pm SD. Pearson's correlations analysis between DEPs and quality traits (cooking loss, Warner-Bratzler shear force,hardness, elasticity and chewiness) of yak meat were performed using SPSS 22.0.

\section{Results and discussion}

\subsection{Quality traits of different parts of yak meat}

WBSF and cooking loss are important indicators reflecting tenderness, Water holding capacity and other qualities of yak meat (Beldarrain et al., 2018; Zhang et al., 2019a). Differences in tenderness and texture are mainly affected by muscle fibers, and studies have shown that the diameter of muscle fibers is positively correlated with muscle hardness, chewiness and WBSF (Yang et al., 2019). As can be seen from Table 1, there were certain differences in tenderness quality among different parts of yak meat. The WBSF and elasticity of JR were significantly lower than that of WJR and HGT $(\mathrm{P}<0.05)$, and the cooking loss was significantly higher than that of WJR and HGT $(\mathrm{P}<0.05)$. The cooking loss of HGT was significantly lower than that of WJR and JR $(\mathrm{P}<0.05)$, while the WBSF, hardness and elasticity of HGT were higher than that of WJR and JR. The results showed that JR tenderness was significantly better than WJR and HGT, while HGT tenderness was poor.

\subsection{Analysis of differentially expressed proteins (DEPs)}

The difference in protein types and structure is an important factor leading to the difference in muscle quality. Studies have shown that DEPs have certain effects on cooking loss, color, tenderness, Water holding capacity and other aspects of muscle with different ages, genders, feeding and altitude (Wang et al., 2018b; Zhang et al., 2019a). As can be seen from Figure 1, the three volcanic maps showed the DEPs of JR/HGT, WJR/ HGT and WJR/JR, respectively. Red dots indicate significantly up-regulated of DEPs ( $\mathrm{Fc} \geq 1.2, \mathrm{P} \leq 0.05)$; Green dots indicate significantly down-regulation of DEPs ( $\mathrm{Fc} \leq 0.83, \mathrm{P} \leq 0.05)$. Gray dots indicate that the DEPs is not significant. A total of 2087 DEPs were detected in the three parts of yak meat, and 88 DEPs (including $11 \mathrm{DEPs}$ ) were significantly up-regulated or down-regulated. In the JR/HGT, WJR/HGT and WJR/JR groups, the DEPs were 25, 40 and 34, respectively, of which 23 ,

Table 1. Quality traits of yak meat in difference parts.

\begin{tabular}{crrr}
\hline Quality parameters & \multicolumn{1}{c}{ WJR } & \multicolumn{1}{c}{ JR } & HGT \\
\hline WBSF/kg & $7.43 \pm 0.28 \mathrm{a}$ & $6.53 \pm 0.61 \mathrm{~b}$ & $8.02 \pm 0.40 \mathrm{a}$ \\
cooking loss/\% & $29.04 \pm 1.59 \mathrm{~b}$ & $31.12 \pm 1.36 \mathrm{a}$ & $26.94 \pm 1.09 \mathrm{c}$ \\
hardness/g & $3621.48 \pm 89.1 \mathrm{~b}$ & $4069.31 \pm 65.0 \mathrm{a}$ & $4110.29 \pm 37.6 \mathrm{a}$ \\
elasticity/mm & $2.78 \pm 0.14 \mathrm{a}$ & $2.29 \pm 0.23 \mathrm{~b}$ & $2.89 \pm 0.19 \mathrm{a}$ \\
chewiness/mj & $33.54 \pm 3.67 \mathrm{~b}$ & $37.94 \pm 3.80 \mathrm{a}$ & $36.25 \pm 2.15 \mathrm{a}$ \\
\hline
\end{tabular}

Data are reported as means \pm SD $(n=9)$. Difffferent superscripts in the same row indicate significant difference $(P<.05)$. 

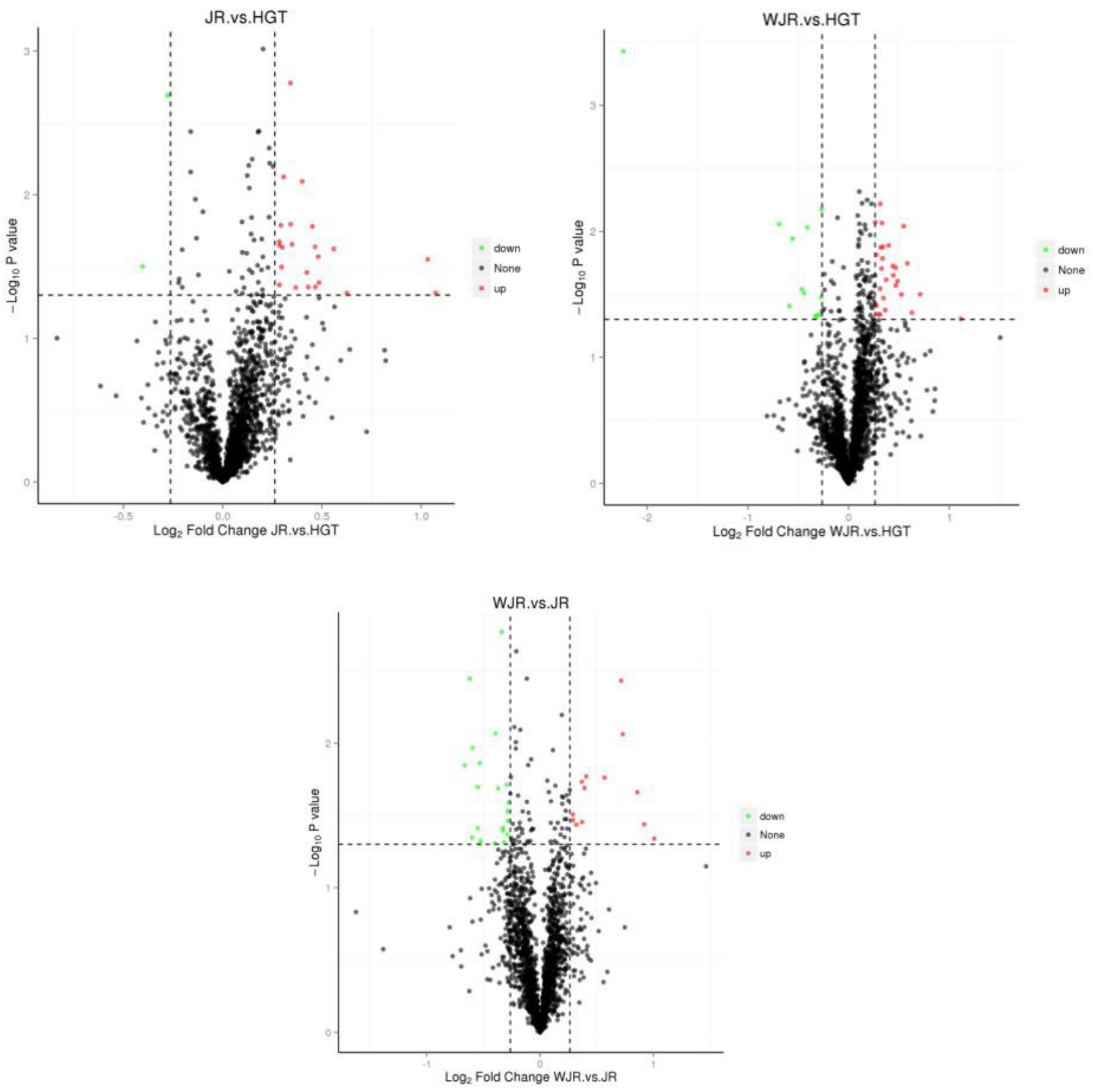

Figure 1. Volcano plots displayed the DEPs of yak meat in difference parts.

28 and 13 were up-regulated proteins, and 2,12 and 21 were down-regulated proteins, respectively (Table 2 ).

\subsection{Correlations between quality traits and significantly DEPs}

Pearson's correlation was used to analyze the correlation between the relative quantitative values of 48 significantly DEPs in WJR/JR and WJR/HGT groups (excluding proteins with uncertain function, fragments and duplicative proteins) and cooking loss, hardness, elasticity, chewiness and WBSF of WJR. As shown in Table 3, 12 of the 48 DEPs were significantly correlated with meat quality, including collagen, structural proteins, heat shock proteins
Table 2. DEPs numbers of yak meat in difference parts.

\begin{tabular}{cccc}
\hline Compared Samples & JR/HGT & WJR/HGT & WJR/JR \\
\hline Num. of Total Quant. & 2807 & 2807 & 2807 \\
Num. of Total Sig. & 25 & 40 & 34 \\
Num. of Sig.Up & 23 & 28 & 13 \\
Num. of Sig.down & 2 & 12 & 21 \\
\hline
\end{tabular}

and protein kinase. The WBSF, cooking loss and texture quality were mainly affected by structural proteins, which were well correlated with A0A3Q1LQC6, A0A452DJI6, F6RP72, Q0VBZ1, Q1JQB0, F1N3I4, F1MZX6 and A0A3Q1LHR1.F1N3I4 had 
Table 3. Pearson's correlation between DEPs and quality traits of yak meat in difffferent parts.

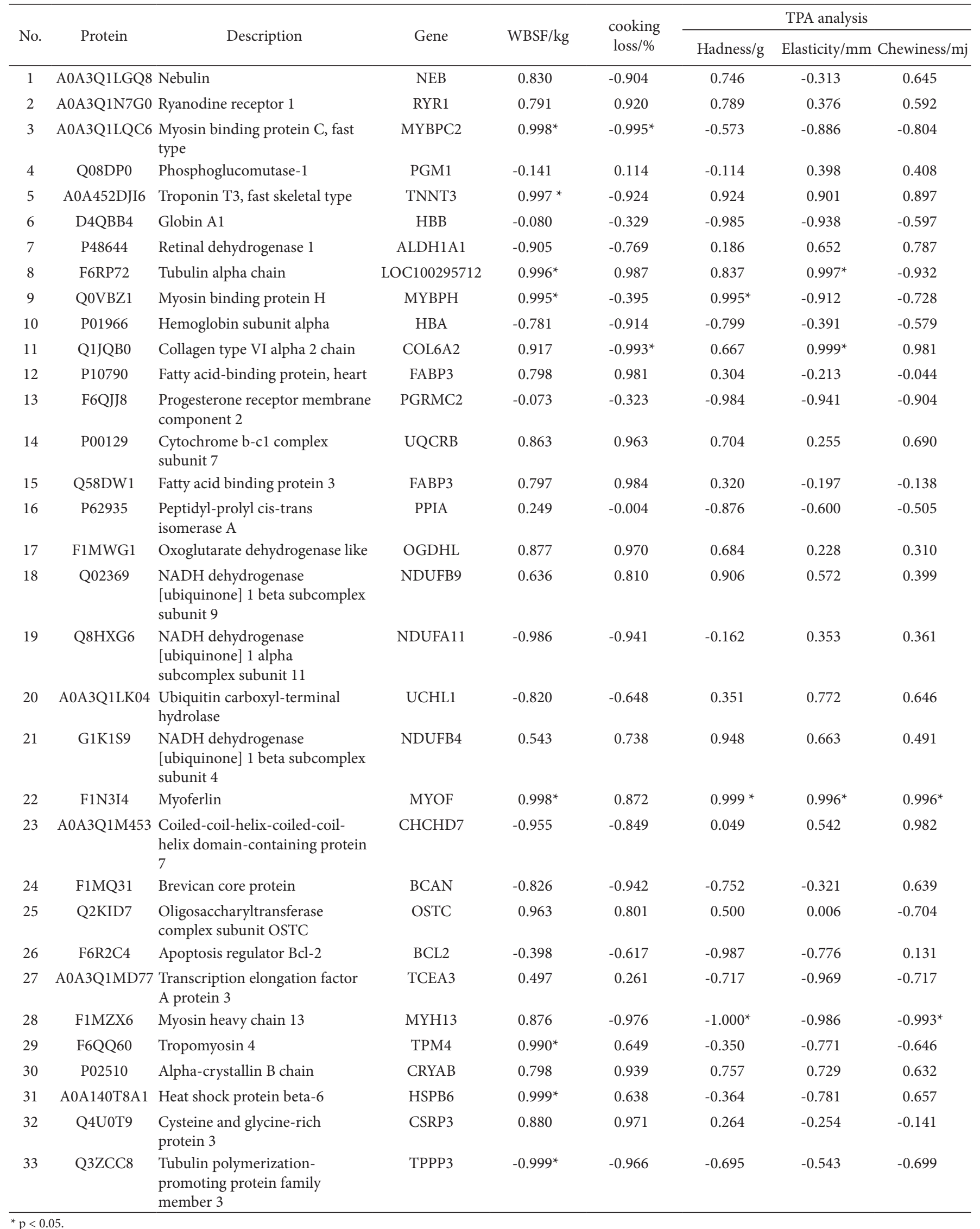


Table 3. Continued...

\begin{tabular}{|c|c|c|c|c|c|c|c|c|}
\hline \multirow[b]{2}{*}{ No. } & \multirow[b]{2}{*}{ Protein } & \multirow[b]{2}{*}{ Description } & \multirow[b]{2}{*}{ Gene } & \multirow[b]{2}{*}{ WBSF/kg } & \multirow{2}{*}{$\begin{array}{l}\text { cooking } \\
\text { loss } / \%\end{array}$} & \multicolumn{3}{|c|}{ TPA analysis } \\
\hline & & & & & & Hadness/g & Elasticity/mm & Chewiness/mj \\
\hline 34 & A0A3Q1LHR1 & Myosin heavy chain 15 & MYH15 & 0.942 & -0.164 & $0.999^{*}$ & $-1.000^{*}$ & $1.000^{*}$ \\
\hline 36 & F1N7X3 & $\begin{array}{l}\text { Nucleosome assembly protein } \\
\text { 1-like } 4\end{array}$ & NAP1L4 & 0.500 & 0.265 & -0.714 & -0.968 & -0.719 \\
\hline 39 & F1MJX9 & Protein kinase $\mathrm{C}$ & PRKCA & 0.965 & 0.987 & 0.400 & -0.112 & -0.005 \\
\hline 40 & A0A3Q1M5Q1 & $\begin{array}{l}\text { Endoplasmic reticulum resident } \\
\text { protein } 44\end{array}$ & ERP44 & -0.919 & -0.789 & 0.155 & 0.628 & 0.692 \\
\hline 41 & F1MUT0 & $\begin{array}{l}\text { Histone-lysine } \\
\text { N-methyltransferase SETD7 }\end{array}$ & SETD7 & -0.970 & -0.877 & -0.005 & 0.496 & 0.399 \\
\hline 44 & G5E518 & Cyclin-dependent kinase 12 & CDK12 & $-0.997^{*}$ & 0.474 & -0.540 & -0.888 & -0.856 \\
\hline 45 & A5PJZ5 & $\begin{array}{l}\text { Nuclear pore complex protein } \\
\text { Nup93 }\end{array}$ & NUP93 & -0.857 & -0.699 & 0.286 & 0.727 & 0.666 \\
\hline 46 & P21282 & $\begin{array}{l}\text { V-type proton ATPase subunit } \\
\text { C } 1\end{array}$ & ATP6V1C1 & 0.288 & 0.037 & -0.856 & -0.776 & -0.540 \\
\hline 47 & A7YY65 & MTCH1 protein & MTCH1 & 0.359 & 0.111 & -0.815 & -0.696 & -0.602 \\
\hline 48 & F1MH20 & Ataxin-10 & ATXN10 & -0.194 & -0.436 & -0.898 & -0.893 & -0.683 \\
\hline
\end{tabular}

significantly correlated with WBSF, hardness, elasticity and chewiness $(\mathrm{r}=0.998,0.999,0.996,0.996 ; \mathrm{P}<0.05)$ and also highly correlated with cooking loss $(\mathrm{r}=0.872)$. In addition, the WBSF was significantly correlated with the DEPs A0A140T8A1 and G5E518 ( $r=0.999,-0.997 ; \mathrm{P}<0.05)$. Some studies have also shown that HSPs is related to muscle shear force at different ages (Wei et al., 2019), myosin heavy chain can significantly affect the texture and quality of muscle (Tian et al., 2016). These marking-related DEPs mainly affect the quality traits of muscle through mechanisms such as carbohydrate metabolism, heat stress and cell apoptosis (Huang et al., 2020).

\subsection{Analysis the expression levels and relative quantitative value of significant correlation DEPs}

As can be seen from Table 4 , the relative quantitative value of 11 DEPs except F6QQ60 have significant difference in different parts of yak meat $(\mathrm{P}<0.05)$. These $\mathrm{DEPs}$ may be the key influencing proteins that cause the differences in the tenderness of WJR, JR and HGT. The relative quantitative value of A0A3Q1LQC6, Q1JQB0 and A0A452DJI6 in JR were significantly lower than those in WJR and HGT $(\mathrm{P}<0.05)$, and the relative quantitative values of A0A3Q1LQC6 were down-regulated compared with those in WJR and HGT. The relative quantitative value of F1MZX6 in HGT was significantly lower than that of JR and WJR $(\mathrm{P}<0.05)$, and the relative quantitative value of F1MZX6 was down-regulated compared with that of JR and WJR. The relative quantitative values of A0A140T8A1 and A0A3Q1LHR1 were significantly higher than those of JR and WJR $(P<0.05)$, and the relative quantitative values of A0A140T8A1 and A0A3Q1LHR1 were up-regulated compared with those of JR and WJR. Therefore, compared with WJR and HGT, it may be that the down-regulation of key DEPs A0A3Q1LQC6, Q1JQB0 and A0A452DJI6 in JR result in the decrease of WBSF and elasticity, resulting in greater cooking loss and better tenderness quality. Compared with WJR and JR, in HGT, due to the down-regulation of F1MZX6 and the up-regulation of A0A140T8A1,A0A3Q1LHR1, the WBSF, hardness and elasticity are larger, resulting in less cooking loss and poor tenderness.

\subsection{Bioinformatics analysis of significantly correlated DEPs}

Through GO annotation, the 12 significantly correlated DEPs were classified. As can be seen from Figure 2, the biological processes involved by significantly correlated DEPs include protein phosphorylation (G5E518), microtubule polymerization (Q3ZCC8) and myoblast fusion (F1N3I4). In the cell components, it is involved in two types of troponin complex (A0A452DJI6) and microtubule (F6RP72). In terms of molecular function, it is involved in ATP binding (F1MZX6, A0A3Q1LHR1, G5E518), structural constituent of eye lens (A0A140T8A1), motor activity (A0A3Q1LHR1), protein binding (A0A3Q1LQC6, Q0VBZ1, F1N3I4, A0A3Q1LHR1, G5E518) and unfolded protein binding (Q1JQB0). The tenderness quality of the three parts of yak meat was mainly affected by 10 biological functions, among which the motor activity, binding protein and unfolded binding protein were the most important factors. 
Table 4. The expression and Relative quantitative value of Significant correlation DEPs.

\begin{tabular}{|c|c|c|c|c|c|c|c|c|}
\hline \multirow{2}{*}{ No. } & \multirow{2}{*}{ Sig.DEPs } & \multirow{2}{*}{ Gene } & \multicolumn{3}{|c|}{ Relative quantitative value } & \multicolumn{3}{|c|}{ Up or Down } \\
\hline & & & WJR & JR & HGT & WJR/JR & WJR/HGT & JR/HGT \\
\hline 1 & A0A3Q1LQC6 & MYBPC2 & $36692.4 \pm 2507.8 \mathrm{a}$ & $27945.3 \pm 3086.6 b$ & $36952.0 \pm 3614.6 \mathrm{a}$ & up & $\mathrm{NA}$ & down \\
\hline 2 & A0A452DJI6 & TNNT3 & $1316.9 \pm 101.6 b$ & $990.1 \pm 29.2 c$ & $1570.2 \pm 134.7 \mathrm{a}$ & up & down & down \\
\hline 3 & F6RP72 & LOC100295712 & $46.9 \pm 3.2 b$ & $71.2 \pm 10.3 \mathrm{a}$ & $62.7 \pm 11.3 \mathrm{ab}$ & down & down & NA \\
\hline 4 & Q0VBZ1 & МYBPH & $96.6 \pm 11.2 b$ & $139.0 \pm 20.2 \mathrm{a}$ & $155.7 \pm 6.7 \mathrm{a}$ & down & down & NA \\
\hline 5 & Q1JQB0 & COL6A2 & $3493.0 \pm 365.0 \mathrm{a}$ & $1847.1 \pm 163.1 \mathrm{c}$ & $2398.3 \pm 135.2 b$ & up & up & down \\
\hline 6 & F1N3I4 & MYOF & $129.1 \pm 19.2 b$ & $195.3 \pm 15.4 \mathrm{a}$ & $178.1 \pm 10.4 \mathrm{a}$ & down & down & $\mathrm{NA}$ \\
\hline 7 & F1MZX6 & MYH13 & $3031.2 \pm 138.1 \mathrm{a}$ & $2904.5 \pm 127.1 \mathrm{a}$ & $2521.2 \pm 100.2 b$ & NA & up & up \\
\hline 8 & F6QQ60 & TPM4 & $198.5 \pm 19.0 \mathrm{a}$ & $208.6 \pm 54.7 \mathrm{a}$ & $228.7 \pm 24.5 \mathrm{a}$ & NA & $\mathrm{NA}$ & NA \\
\hline 9 & A0A140T8A1 & HSPB6 & $124.2 \pm 11.0 \mathrm{~b}$ & $118.2 \pm 10.4 b$ & $197.7 \pm 5.9 \mathrm{a}$ & NA & down & down \\
\hline 10 & Q3ZCC8 & ТРPР3 & $535.4 \pm 38.1 b$ & $708.9 \pm 126.7 \mathrm{a}$ & $711.3 \pm 49.1 \mathrm{a}$ & down & down & NA \\
\hline 11 & A0A3Q1LHR1 & MYH15 & $278.8 \pm 114.6 \mathrm{c}$ & $858.7 \pm 148.2 b$ & $1315.5 \pm 113.8 \mathrm{a}$ & down & down & down \\
\hline 12 & G5E518 & CDK12 & $1786.4 \pm 160.7 \mathrm{a}$ & $1645.8 \pm 161.8 \mathrm{ab}$ & $1388.5 \pm 169.8 b$ & NA & up & NA \\
\hline
\end{tabular}

Data are reported as means $\pm \mathrm{SD}(\mathrm{n}=3)$. Different superscripts in the same row indicate significant difference $(\mathrm{P}<.05)$. Up or Down were significantly up-regulated or down-regulated respectively, and NA is at the same level. NA is neither significantly up-regulated nor down-regulated.

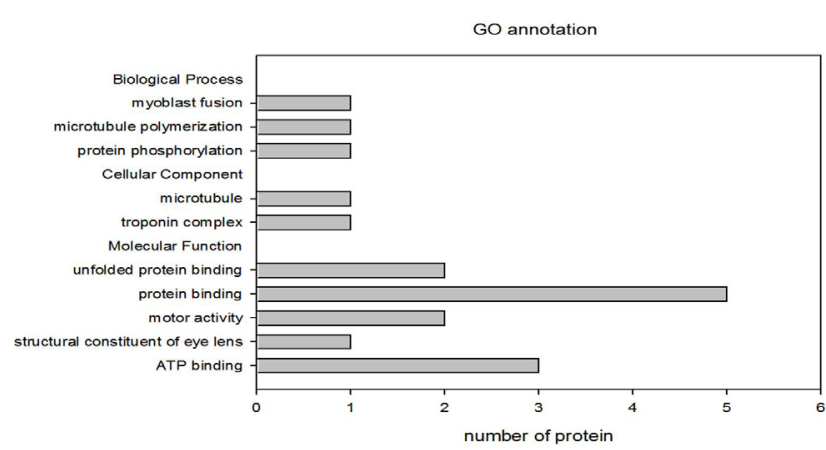

Figure 2. GO analysis of the significantly correlated DEPs.

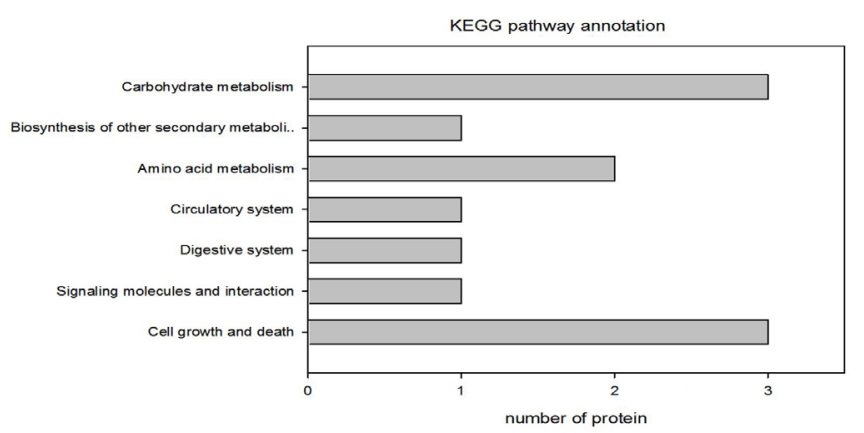

Figure 3. KEGG analysis of the significantly correlated DEPs.

KEGG database was used to analyze the metabolic pathways of significantly correlated DEPs (Figure 3), and the 12 significantly correlated DEPs were involved in a total of 7 metabolic pathways. They mainly concentrate on cell growth and death pathway (F6RP72 A0A3Q1LHR1, Q0VBZ1), signal molecules and interaction pathway (Q1JQB0), digestive system pathway(Q1JQB0), circulatory system pathway (F6QQ60), amino acid metabolic pathway (F1N3I4 A0A140T8A1), biosynthesis of other secondary metabolic pathway (G5E518) and carbohydrate metabolism pathway (A0A3Q1LQC6, A0A452DJI6 F1N3I4). Cell growth and death, amino acid metabolism and carbohydrate metabolism had great effects on the tenderness quality of the three parts of yak meat.

\section{Conclusion}

The difference of muscle proteome in different parts of yak meat and its correlation with tenderness quality were studied by TMT quantitative proteomics. There were 88 significantly DEPs in the three parts, 25, 40 and 34 in the JR/HGT, WJR/ HGT and WJR/JR groups, respectively.There were 23, 28 and 13 up-regulated and 2, 12 and 21 down-regulated in the JR/HGT, WJR/HGT and WJR/JR groups, respectively. Correlation analysis showed that a total of 12 DEPs were significantly correlated with the tenderness quality. The tenderness of the three parts of yak meat was mainly affected by collagen, structural proteins, heat shock proteins, tubulin and protein kinase. Among the 12 DEPs, the relative contents of the 11 DEPs were significantly different in different parts of yak meat $(\mathrm{p}<0.05)$.There were 8 key DEPs in WJR/JR, 9 key DEPs in WJR/HGT, and 6 key DEPs in JR/ HGT. A0A3Q1LQC6, Q1JQB0 and A0A452DJI6 are the key DEPs that cause the difference of tenderness between JR and WJR, HGT. F1MZX6, A0A140T8A1 and A0A3Q1LHR1 are the key DEPs that cause the difference of tenderness between HGT and JR,WJR. The expression of these DEPs in different parts is down-regulated or up-regulated to varying degree, and is closely related to the growth and death of muscle cells, carbohydrate metabolism, amino acid metabolism, protein binding and motor activity, and unfolded protein binding. The different expression levels of these key DEPs in different parts and different metabolic pathways are related to the tenderness of WJR, JR and HGT, which provides data reference for further research. 


\section{Acknowledgements}

This work was supported by the Qinghai Science and Technology Plan Projects (Project No. 2016NKA7), Fundamental Research Projects of Academy of Animal Sciences and Veterinary Medicine of Qinghai University (Project No. MKY201802) and the Qinghai Province " thousand and high-end creative talent plan"Project.

\section{References}

Almeida, A. M., Bassols, A., Bendixen, E., Bhide, M., Ceciliani, F., Cristobal, S., Eckersall, P. D., Hollung, K., Lisacek, F., Mazzucchelli, G., McLaughlin, M., Miller, I., Nally, J. E., Plowman, J., Renaut, J., Rodrigues, P., Roncada, P., Staric, J., \& Turk, R. (2015). Animal board invited review: advances in proteomics for animal and food sciences. Animal, 9(1), 1-17. http://dx.doi.org/10.1017/S1751731114002602. PMid:25359324.

Beldarrain, L. R., Aldai, N., Picard, B., Sentandreu, E., Navarro, J. L., \& Sentandreu, M. A. (2018). Use of liquid isoelectric focusing (OFFGEL) on the discovery of meat tenderness biomarkers. Journal of Proteomics, 183, 25-33. http://dx.doi.org/10.1016/j.jprot.2018.05.005. PMid:29751105.

Cao, M., Cao, A., Li, Y., Wang, W., Wang, Y., \& Cai, L. (2019). Effects of magnetic nanoparticles plus microwave on the thawing of largemouth bass (Micropterus salmoides) fillets based on iTRAQ quantitative proteomics. Food Chemistry, 286, 506-514. http://dx.doi. org/10.1016/j.foodchem.2019.02.051. PMid:30827639.

Chen, M. Y., Tian, Y., Yu, Q. L., Han, L., Zhao, S. N., \& Song, R. D. (2020). Effect of a low-voltage electrical stimulation on yak meat tenderness during postmortem aging. Animal Science Journal, 91(1), e13410. http://dx.doi.org/10.1111/asj.13410. PMid:32583539.

Gagaoua, M., Bonnet, M., Ellies-Oury, M. P., De Koning, L., \& Picard, B. (2018). Reverse phase protein arrays for the identification/validation of biomarkers of beef texture and their use for early classification of carcasses. Food Chemistry, 250, 245-252. http://dx.doi.org/10.1016/j. foodchem.2018.01.070. PMid:29412918.

Gao, M. R., Xu, Q. D., \& Zeng, W. C. (2020). Effect of tea polyphenols on the tenderness of yak meat. Journal of Food Processing and Preservation, 44(5), e14433. http://dx.doi.org/10.1111/jfpp.14433.

Guo, Z., Ge, X., Yang, L., Ma, G., Ma, J., Yu, Q. L., \& Han, L. (2021). Ultrasound-assisted thawing of frozen white yak meat: Effects on thawing rate, meat quality, nutrients, and microstructure. Ultrasonics Sonochemistry, 70, 105345. http://dx.doi.org/10.1016/j. ultsonch.2020.105345. PMid:32932225.

Hardie, D. G., Ross, F. A., \& Hawley, S. A. (2012). AMPK: a nutrient and energy sensor that maintains energy homeostasis. Nature Reviews. Molecular Cell Biology, 13(4), 251-262. http://dx.doi.org/10.1038/ nrm3311. PMid:22436748.

Hou, X., Liang, R., Mao, Y., Zhang, Y., Niu, L., Wang, R., Liu, C., Liu, Y., \& Luo, X. (2014). Effect of suspension method and aging time on meat quality of Chinese fattened cattle M. Longissimus dorsi. Meat Science, 96(1), 640-645. http://dx.doi.org/10.1016/j. meatsci.2013.08.026. PMid:24056407.

Huang, C., Hou, C., Ijaz, M., Yan, T., Li, X., Li, Y., \& Zhang, D. (2020). Proteomics discovery of protein biomarkers linked to meat quality traits in post-mortem muscles: current trends and future prospects: a review. Trends in Food Science \& Technology, 105, 416-432. http:// dx.doi.org/10.1016/j.tifs.2020.09.030

Jones, P., Binns, D., Chang, H. Y., Fraser, M., Li, W., McAnulla, C., McWilliam, H., Maslen, J., Mitchell, A., Nuka, G., Pesseat, S., Quinn,
A. F., Sangrador-Vegas, A., Scheremetjew, M., Yong, S. Y., Lopez, R., \& Hunter, S. (2014). InterProScan 5: genome-scale protein function classification. Bioinformatics (Oxford, England), 30(9), 1236-1240. http://dx.doi.org/10.1093/bioinformatics/btu031. PMid:24451626.

Li, X. R., Shi, X. X., Wang, J. Z., Zhang, P. G., Tian, Z., \& Han, L. (2020). Effect of nitric oxide synthetase inhibitor on yak meat quality during post-mortem aging. Zhongguo Nong Ye Ke Xue, 53(08), 1617-1626.

McCarthy, S. N., Henchion, M., White, A., Brandon, K., \& Allen, P. (2017). Evaluation of beef eating quality by Irish consumers. Meat Science, 132, 118-124. http://dx.doi.org/10.1016/j.meatsci.2017.05.005. PMid:28522169.

Park, K. M., Pramod, A. B., Kim, J. H., Choe, H. S., \& Hwang, I. H. (2010). Molecular and biological factors affecting skeletal muscle cells after slaughtering and their impact on meat quality: A mini review. Journal of Muscle Foods, 21(2), 280-307. http://dx.doi. org/10.1111/j.1745-4573.2009.00182.x.

Shi, J., Zhang, L., Lei, Y., Shen, H., Yu, X., \& Luo, Y. (2018). Differential proteomic analysis to identify proteins associated with quality traits of frozen mud shrimp (Solenocera melantho) using an iTRAQ-based strategy. Food Chemistry, 251, 25-32. http://dx.doi.org/10.1016/j. foodchem.2018.01.046. PMid:29426420.

Taye, M., Yoon, J., Dessie, T., Cho, S., Oh, S. J., Lee, H. K., \& Kim, H. (2018). Deciphering signature of selection affecting beef quality traits in Angus cattle. Genes \& Genomics, 40(1), 63-75. http://dx.doi. org/10.1007/s13258-017-0610-z. PMid:29892901.

Tian, J. C., Han, L., Yu, Q. L., Shi, X. X., \& Wang, W. T. (2013). Changes in tenderness and cathepsins activity during post mortem ageing of yak meat. Canadian Journal of Animal Science, 93(3), 321-328. http://dx.doi.org/10.4141/cjas2012-102.

Tian, X., Wu, W., Yu, Q., Hou, M., Jia, F., Li, X., \& Dai, R. (2016). Quality and proteome changes of beef $\mathrm{M}$. longissimus dorsi cooked using a water bath and ohmic heating process. Innovative Food Science \& Emerging Technologies, 34, 259-266. http://dx.doi.org/10.1016/j. ifset.2016.02.013

Wang, L. L., Han, L., Ma, X. L., Yu, Q. L., \& Zhao, S. N. (2017). Effect of mitochondrial apoptotic activation through the mitochondrial membrane permeability transition pore on yak meat tenderness during postmortem aging. Food Chemistry, 234, 323-331. http:// dx.doi.org/10.1016/j.foodchem.2017.04.185. PMid:28551242.

Wang, L. L., Yu, Q. L., Han, L., Ma, X. L., Song, R. D., Zhao, S. N., \& Zhang, W. H. (2018a). Study on the effect of reactive oxygen speciesmediated oxidative stress on the activation of mitochondrial apoptosis and the tenderness of yak meat. Food Chemistry, 244, 394-402. http://dx.doi.org/10.1016/j.foodchem.2017.10.034. PMid:29120799.

Wang, L., Ma, G., Zhang, Y., Shi, X., Han, L., Yu, Q., Zhao, S., \& Ma, J. (2018b). Effect of mitochondrial cytochrome c release and its redox state on the mitochondrial-dependent apoptotic cascade reaction and tenderization of yak meat during postmortem aging. Food Research International, 111, 488-497. http://dx.doi.org/10.1016/j. foodres.2018.05.049. PMid:30007711.

Wang, Z., He, F., Rao, W., Ni, N., Shen, Q., \& Zhang, D. (2016). Proteomic analysis of goat Longissimus dorsi muscles with different drip loss values related to meat quality traits. Food Science and Biotechnology, 25(2), 425-431. http://dx.doi.org/10.1007/s10068-016-0058-y. PMid:30263286.

Wei, Y., Li, X., Zhang, D., \& Liu, Y. (2019). Comparison of protein differences between high-and low-quality goat and bovine parts based on iTRAQ technology. Food Chemistry, 289, 240-249. http:// dx.doi.org/10.1016/j.foodchem.2019.03.052. PMid:30955608. 
Yang, Y. Y., Zhang, Y. M., \& Mao, Y. W. (2019). Differences in myofifiber characteristics and meat quality of different yak muscles. Shipin Kexue, 40(21), 72-77.

Yu, Q., Tian, X., Shao, L., Xu, L., Dai, R., \& Li, X. (2018). Label-free proteomic strategy to compare the proteome differences between longissimus lumborum and psoas major muscles during early postmortem periods. Food Chemistry, 269, 427-435. http://dx.doi. org/10.1016/j.foodchem.2018.07.040. PMid:30100455.

Zhang, L., Sun, B., Xie, P., Li, H., Su, H., Sha, K., Huang, C., Lei, Y., Liu, X., \& Wang, H. (2015). Using near infrared spectroscopy to predict the physical traits of Bos grunniens meat. Lebensmittel-Wissenschaft + Technologie, 64(2), 602-608. http://dx.doi.org/10.1016/j.lwt.2015.06.022.

Zhang, M., Wang, D., Xu, X., \& Xu, W. (2019a). Comparative proteomic analysis of proteins associated with water holding capacity in goose muscles. Food Research International, 116, 354-361. http://dx.doi. org/10.1016/j.foodres.2018.08.048. PMid:30716956.

Zhang, Y., Ji, X., Mao, Y., Luo, X., Zhu, L., \& Hopkins, D. L. (2019b). Effect of new generation medium voltage electrical stimulation on the meat quality of beef slaughtered in a Chinese abattoir. Meat Science, 149, 47-54. http://dx.doi.org/10.1016/j.meatsci.2018.11.011. PMid:30453280.

Yan, Z.X., LI, W., Hu, R., Ma, Q.M., \& Lu, Z.M. (2021). Quantitative proteomic comparison of protein differences in different parts of yak meat. Food Science and Technology (Campinas). In press. http:// dx.doi.org/10.1590/fst.62020.

Zuo, H., Han, L., Yu, Q., Niu, K., Zhao, S., \& Shi, H. (2016). Proteome changes on water-holding capacity of yak longissimus lumborum during postmortem aging. Meat Science, 121, 409-419. http://dx.doi. org/10.1016/j.meatsci.2016.07.010. PMid:27448195. 